\title{
OCCUPATIONAL EXPOSURE OF OPERATING ROOM PERSONNEL TO TRICHLORETHYLENE
}

\author{
Thomas H. Conbett, M.D., Glenn C. Hamilton, B.s., Myung K. Yoon, M.d., and \\ JUUDY L. ENDRES, B.S.
}

\section{INTRODUCTION}

Trichlonetrylene is unique among anaesthetic agents in that it is also used widely as an industrial solvent. As a result, chronic toxicity studies of TCE have been performed in greater amounts than for other anaesthetic agents. The threshold limit value for TCE has been set at $100 \mathrm{ppm}$.

In 1970, Stewart et al. ${ }^{1}$ reported ten experimental human exposures to TCE, 100 and $200 \mathrm{ppm}$, for periods of one hour to a five-day work-week. The only troublesome response was a sensation of mild fatigue and sleepiness in five subjects during the fourth and fifth consecutive days of exposure to $200 \mathrm{ppm}$. Following single exposures of $200 \mathrm{ppm}$ for one hour and $100 \mathrm{ppm}$ for four hours, TCE was detectable in end-expired air of subjects for 44 and 38 hours, respectively.

A recent study by Salvini et $a .^{2}$ has demonstrated that $110 \mathrm{ppm}$ TCE administered to volunteers for four-hour periods resulted in a significant decrease in performance of standard psychophysiological tests. These authors suggest that the recommended TLV appears very close to the concentration capable of interfering with psychophysiological efficiency, even in the absence of other undesirable subjective or objective manifestations.

In light of these findings, we determined the range of concentrations of TCE in the operating room during administration of TCE anaesthesia under usual working conditions, and measured end-expired breath levels of TCE in patients following TCE anaesthesia and in anaesthetists following administration of anaesthesia.

\section{METHODS}

Trichlorethylene anaesthesia was administered to six patients for periods ranging from 75-160 minutes using a non-rebreathing system with a Sierra valve. A total gas flow of $9 \mathrm{~L} / \mathrm{min}$ was used. TCE was administered using a Vernitrol vaporizer, with concentrations ranging between 0.25 per cent and 1.0 per cent.

TCE concentrations were measured in parts per million, using a Beckman GC 72-5 gas chromatograph with a flame ionization detector. The limit of detection was $10 \mathrm{ppb}$.

Operating-room concentrations were determined in five separate areas of the operating room. Operating-room air was collected by slowly withdrawing samples into a large gas-tight syringe. Samples were injected into Saran bags and taken to

From The Department of Anaesthesiology, University of Michigan Medical School and U.S. Veterans Administration Hospital, Ann Arbor, Michigan 48105, U.S.A. 
TABLE I

Concentrations of Trichlorethylene in the Operating Room

\begin{tabular}{llll}
\hline \hline & & \multicolumn{2}{c}{ PPM Trichlorethylene } \\
\cline { 2 - 4 } \multicolumn{1}{c}{ Location } & & \multicolumn{1}{c}{$30 \mathrm{~min}$} & \multicolumn{1}{c}{$60 \mathrm{~min}$} \\
\hline Directly over valve $\left[4^{\prime}\right]$ & Range & $1-81(6)$ & $1-103(5)$ \\
& Mean & $\mathbf{2 5}$ & 30 \\
One foot from valve $\left[4^{\prime}\right]$ & Range & $1-11(6)$ & $1-9(5)$ \\
& Mean & 3 & 4 \\
Two feet from valve $\left[4^{\prime}\right]$ & Range & $0.2-1.4(6)$ & $0.5-2.4(5)$ \\
& Mean & $\mathbf{0 . 8}$ & 1.2 \\
Foot of O.R. Table $\left[5^{\prime}\right]$ & Range & $0.5-1.4(6)$ & $0.4-0.9(5)$ \\
& Mean & 0.8 & 0.7 \\
Corner of room $\left[5^{\prime}\right]$ & Range & $\mathbf{0 . 2 - 0 . 7 ( 5 )}$ & $0.2-0.8(5)$ \\
& Mean & $\mathbf{0 . 5}$ & 0.6 \\
\hline
\end{tabular}

Concentrations of TCE in various locations after 30 and 60 minutes of anaesthesia. Numbers in parentheses indicate number of samples in each group. Number in brackets indicate height above floor at which samples were taken. The two highest levels, 81 and $103 \mathrm{ppm}$, occurred during a case where the anaesthetist and anaesthetic machine were partially enclosed in a tent of surgical drapes.

the laboratory for analysis. Samples were taken directly above the expiratory valve, one foot, and two feet from the valve, all at levels four feet above the floor. In addition, samples were collected at the foot of the operating table, and in the far corner of the room away from the anaesthetists and five feet above the floor. Samples were collected at 30 and 60 minutes following induction of anaesthesia. The air turnover rate in the operating rooms was 12 times per hour.

The rates of excretion of TCE were determined in three patients and in three anaesthetists by measuring concentrations in end-expired air of subjects at intervals following exposure. Samples were collected in Saran bags. Subjects were instructed to inhale, exhale about two-thirds, and then breathe into the bag.

\section{Results}

Operating room air concentrations of trichlorethylene ranged from $0.2 \mathrm{ppm}$ in the periphery of the room to $103 \mathrm{ppm}$ at a level of four feet directly over the expiratory valve. Average concentrations in each area measured are listed in Table I.

Three patients had detectable levels of TCE in end-expired air for 4, 11, and 12 days following TCE anaesthesia for 30,100 and 160 minutes, respectively, as shown in Figure 1.

Three anaesthetists had detectable levels of TCE in end-expired air from 2 to 7 hours following termination of administration of routine clinical anaesthesia ranging from 60 to 150 minutes in duration (Figure 2).

\section{Discussion}

The study by Salvini et al. raises the question of another possible occupational hazard in the operating-room environment. Does exposure to low levels of anaesthetic gases impair judgment and ability to react rapidly when the situation 


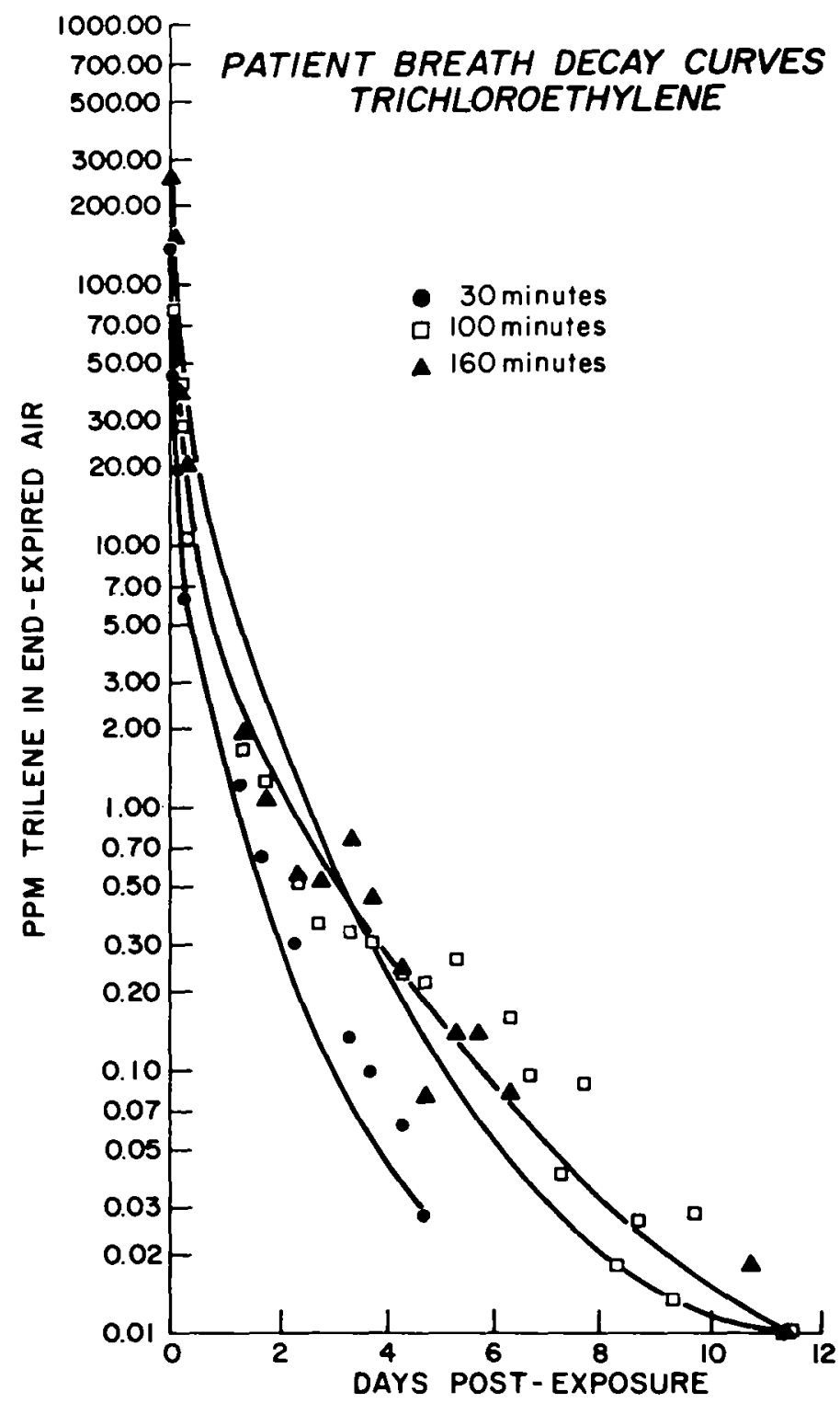

Frcure 1. Trichlorethylene breath decay curves for three patients exposed to TCE anaesthesia-30,100, 160 minutes.

requires it? Our study of operating-room levels of TCE during anaesthesia has demonstrated that these levels are reached near the expiratory valve during cases when the anaesthetic machine and anaesthetist are partially enclosed in a tent of surgical drapes. Furthermore, $110 \mathrm{ppm}$ was the lowest level studied by Salvini et $\mathrm{al}$. and the concentrations impairing mental functions may be considerably lower.

The possible impairment of psychophysiological function by operating room concentrations of other anaesthetic gases should be studied. 


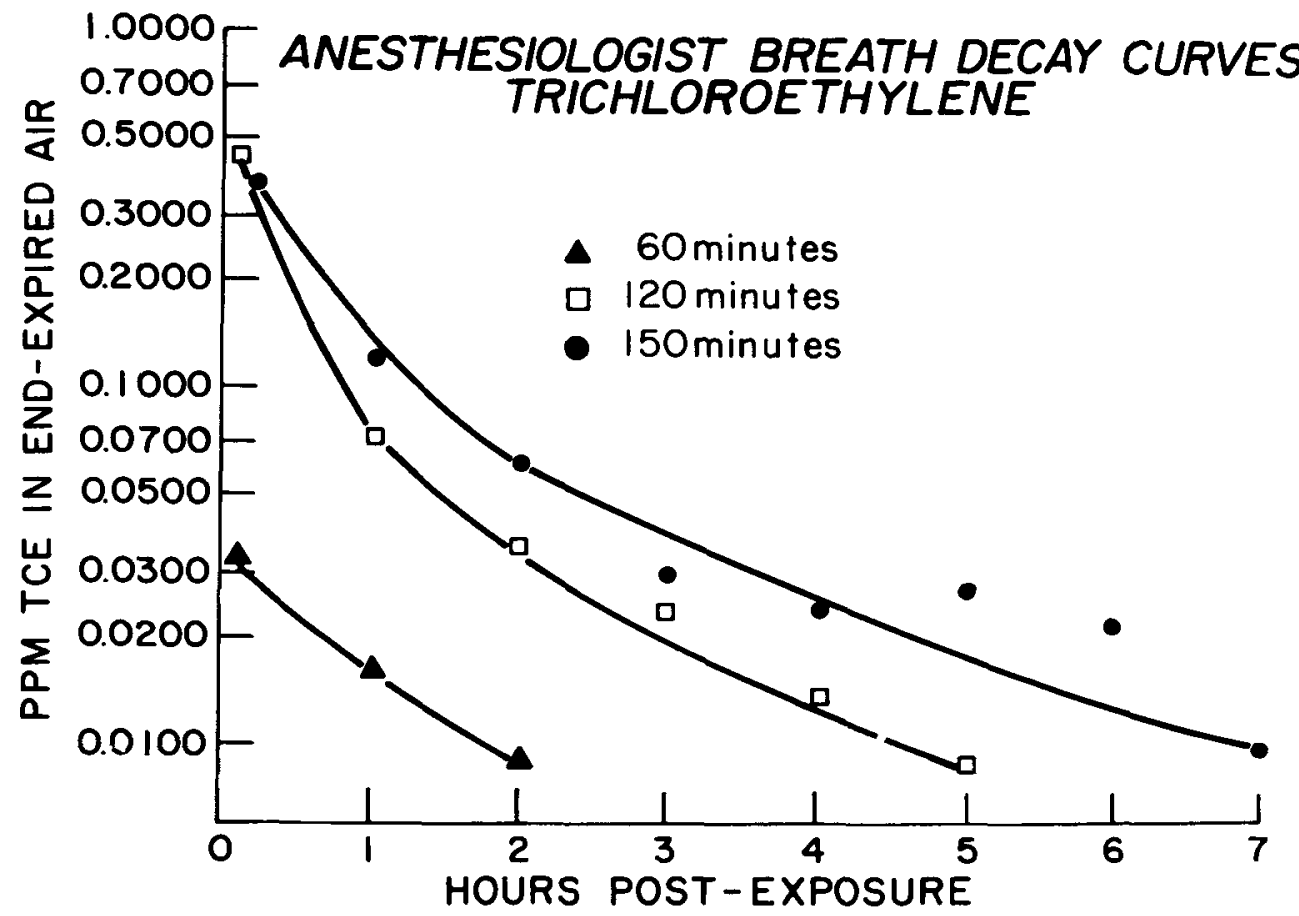

Figure 2. Trichlorethylene breath decay curves for anaesthetists following occupational exposures of 60,120 , and 150 minutes.

\section{RÉsUMÉ}

Nous avons mesuré les concentrations de trichloréthylene aussi bien dans l'atmosphère de la salle d'opération et à la fin de l'expiration des anesthésistes au cours et à la suite de l'administration de trichloréthylene. La concentration la plus élevée de trichloréthylene dans la salle d'opération était de 103 ppm (parties par million) et est survenue durant une anesthésie où l'anesthésiste lui-même et la machine à anesthésie étaient partiellement enfermés dans une tente avec des champs chirurgicaux. La plupart des taux variaient entre 2 et $14 \mathrm{ppm}$. A la fin d'expiration des anesthésistes, le trichloréthylene était mesurable jusqu'à sept heures après un travail professionnel de routine.

Les concentrations de chloréthylene à la fin d'expiration des malades soumis à une anesthésie au chloréthylene étaient dépistables jusqu'à onze jours après la fin de l'anesthésie.

\section{ACKNOWLEDGMENTS}

This project was supported by Veterans Administration Research Funds.

\section{REFERENCES}

1. Stewart, R.D., Dod, H.C., \& Gay, H.H., et al. Experimental human exposure to trichloroethylene. Arch Environ Health 20: 64-71 (1970).

2. Salvini, M., Binaschi, S., \& Riva, M. Evaluation of psychophysiological functions in humans exposed to trichloroethylene. Brit. J. Industr. Med. 28: 293-295 (1971). 